\title{
A Study on the Loss Reduction Method of Reinforcing Bar through Case Study
}

\author{
Park, U-Yeol ${ }^{1 *} \quad$ Jung, Hyeon-Ok ${ }^{2} \quad$ Kang, Tai-Kyung ${ }^{3}$ Cho, Hun-Hee ${ }^{4}$ \\ Department of Architectural Engineering, Andong University, Andong-Si, Gyeongsangbuk-Do, 760-749, Korea ${ }^{1}$ \\ Graduate School,. Department of Architecture, Korea University, Seongbuk-Gu, Seoul, 136-701, Korea ${ }^{2}$ \\ Cost Engineering Research Center, Korea Institute of Construction Technology, Goyang-Si, Gyeonggi-Do, 411-712, \\ Korea ${ }^{3}$ \\ School of Civil, Environmental and Architectural Engineering, Korea University, Seongbuk-Gu, Seoul, 136-701, \\ Korea $^{4}$
}

\begin{abstract}
Rebar work accounts for approximately $30 \%$ of the total construction costs for rebars and concrete. Recently, the higl rising prices of rebars have become one of the principle factors of rising construction costs. Therefore, constructior companies are putting much effort into loss reduction of rebars. Consequently, in this study, we wished to present los: reduction methods of rebars before the preparation of the placing drawings. To devise such methods, we collectec previous case studies and analyzed methods that were applied for loss reduction. As a result of the analysis, we wer able to find the following methods for loss reduction of rebars: method of reducing the number of splices at the ma foundation, method of reducing splice length at the internal columns or walls of the underground parking lot, method o reducing cap-ties of internal beams of basement floors excluding perimeter beams, and method of reducing anchorags length at the internal column or wall of the underground parking lot. Based on those analysis results, we presented ou own loss reduction methods of rebars. Applying our methods resulted in considerable loss reduction.
\end{abstract}

Keywords : Reinforced Concrete, Placing Drawings, Reinforcing Bar Details, Loss, Constructability

\section{Introduction}

\subsection{Research Background and Objective}

Reinforcing bars (hereafter referred to as "rebar") not only impact greatly the quality of the reinforced concrete structure but they also account for approximately $30 \%$ of the concrete construction costs and can be seen as taking a very significant portion of raw material costs [1]. Furthermore, the raw material costs has risen as shown in Figure 1. Likewise, the cost of rebars has increased more than two-fold. Consequently, rebar stockpiling has

Received : June 30, 2010

Revision received : July 16, 2010

Accepted : July 23, 2010

* Corresponding author:

[Tel: 82-54-820-5897, E-mail: wypark@ andong.ac.kr]

(c)2010 The Korea Institute of Building Construction, All rights reserved. occurred and construction has been delayed from time to time because companies have been facing difficulties in precuring rebars. Because of such circumstances, many construction companies are putting much efforts into cutting down construction raw material costs through loss reduction of rebars.

In addition, when looking into structural design standards related to rebars, most reinforced concrete structures are being designed using the ultimate strength design method ever since the legislation of the $\ulcorner$ Code on Reinforced Concrete Structure Calculation Using the Ultimate Strength Design Method」 in 1988. Additionally, in 1999, domestic code was legislated by the joint efforts of AIJ(Architectural Institute of Korea) and $\mathrm{KCI}$ (Korea Concrete Institute) and thus allowed for a standard that could be applied together for both fields[2]. Afterwards, revised standards were published in 2003 and 2007 and are being applied to structure designs. 


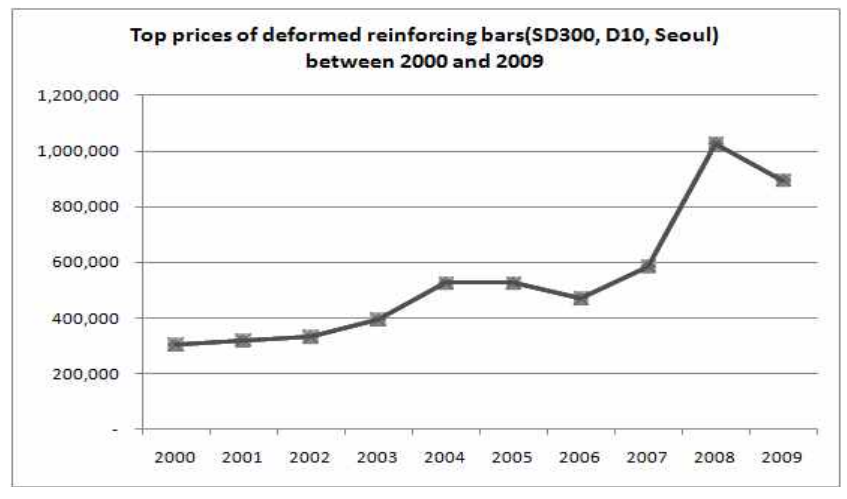

Figure 1. Top prices of deformed reinforcing bars (SD300, D10, Seoul) between 2000 and 2009

As we have described above, new domestic code have been established which were non-existent in the past and therefore many cases are now being presented in which the standard for rebar details is not clear. Furthermore, we also have reports of cases in which although loss reduction for the rebars is possible, rebars were overtly used to increase the constructability in accordance with previous construction practices[3]. Likewise, in spite of the fact that the rebar length can be shortened through improvements in rebar arrangement and through structure review, rebars are being used unnecessarily. Such use can also be considered as loss. To reduce such loss, reduction measures should be reflected even before the placing drawings are prepared - i.e. when the rebar details are decided. The measures should be devised in accordance with the current domestic code.

Therefore, in our study, as part of a series of studies to develop a procurement system for rebar materials, we wish to present various loss reduction methods of rebars before preparing the placing drawings - i.e. when the rebar details are decided. Through such methods, our objective is to cut framework construction costs and to strengthen the price competitiveness of structure constructions.

\subsection{Scope and Method of Study}

Loss reduction methods of rebars can be presented in various ways. One method would be the method proposed by Kim et al [4] and Kim et al [5]. For this method, attention is first given to the loss that occurs when rebars are cut to meet the standard lengths set by steel companies. Then a optimization measure is proposed to minimize this loss. This method can be applied at the ordering stage of the rebars after the placing drawings are prepared and after the shapes and length of the rebar shown on the bar list have been reviewed.

However, the scope of our study has been limited to presenting only those methods of loss reduction that can be applied before the preparation of the placing drawings.

First, we reviewed over previous studies on loss reduction methods of rebars to analyze their limitations. Next, we conducted interview surveys on case studies of loss reductions done by detailers. In addition, based on the case studies prepared by detailers, we analyzed the different methods that were applied for loss reduction. For such case studies, we also analyzed the placing drawings to analyze the efficiency and actual loss that was reduced. Based on the analysis results of the methods that were used in the various case studies, we proposed our own loss reduction method for rebars. To verify the efficiency of our proposed method, we applied our method to a case that had no loss reduction method applied to it and analyzed the feasibility of our method.

\section{Review of Previous Studies}

The following are the major categories of studies done on rebar loss: rebar loss analysis through actual condition surveys, proposals of optimal combination algorithms for loss reduction, and other loss reduction methods and economic feasibility studies.

For studies done on actual conditions, there is the study on rebar loss and erection bars. Cho et al [1] analyzed rebar construction conditions of Korean apartments focusing on rebar loss. In other words, they investigated and analyzed the amount of rebar that were produced and then were handled as scrap metal. Based on their analysis results, they concluded that there was significant loss of rebar on site of rebar fabricating. Park et al [2] analyzed the actual conditions of rebar arrangement in Korea and proposed measures for improvement. They especially analyzed the simplification 
of the rebar lengths as related to rebar loss, and analyzed the changes in the quantity of rebar used when manufacturing lengths were simplified. Jung et al [6] analyzed the actual conditions of erection bars that had no structural role but were inevitably used to place the main rebars. To solve the excessive usage of erection bars, they proposed a method to improve the placement of the erection bars.

During the beginning of the 1990s, there was a study on how to assemble fabricated rebars in size with the standard length. Kim et al [4] proposed a loss reduction method of rebars in the aspect of construction management. Based on rebar lengths extracted from placing drawings, they solved for the optimal combination that produces a consistent loss rate and then proposed a optimal algorithm that would solve for a custom rebar length. Kim et al [5] proposed a optimization method for each floor unit since onsite construction is done at one floor unit at a time. They defined optimization as the standard length that will incur the least loss rate if the rebars are ordered and cut at that length.

In addition to the above studies, Kim et al [7], [8] looked into the recently used SD 500 rebars and compared the cost aspect for the lap splice and the coupler splice. They proposed that as the rebar diameter got bigger and the concrete strength got lower, coupler splices showed to be more economically feasible than the lap splices. Park et al [9], for beam and slab members that are arranged continuously using standard-length rebars, proposed a genetic algorithm that makes possible compressed connection in the connection section regulated by specifications and combines optimal standard-length rebars that generate the least loss. Cho et al [10] pointed out unnecessary rebar loss due to unplanned rebar cutting and bending at construction sites instead of following rebar fabricating plans that are appropriate for the construction. They then proposed a standardization plan for manufacturing rebar forms.

As we have described in detail, there have been various studies done on loss reduction of the rebar. However, the studies present methods that can only be utilized at the ordering stage or present a method of changing the rebar connection to a coupler splice. We could not find any study that presented a method on loss reduction prior to the preparation of the placing drawings.

\section{Analysis of Case Studies}

In this chapter, we analyzed the loss that was reduced for each case study based on the placing drawing that was actually applied. The length of lap splice and development can be different for each structural drawing. Therefore, we analyzed the loss based on the length that was indicated on the structural drawing. In addition, in some case studies, the loss reduction method was applied to only partial areas or only on some of the floors. In these cases, it was difficult to investigate the total loss of the project and therefore, we analyzed the reduced loss only on the areas that the method was applied.

\subsection{Reduction of Splices}

\subsubsection{Reduction of splices at the foundation}

As modern architectures have become larger, more often than not, mat foundations are being used. The bigger the building is the bigger the mat foundation becomes. Then, if $8 \mathrm{~m}$ rebars which is the standard length of steel companies are used, there will be many splices, and there will be as much rebar loss as the length of the lap splice.
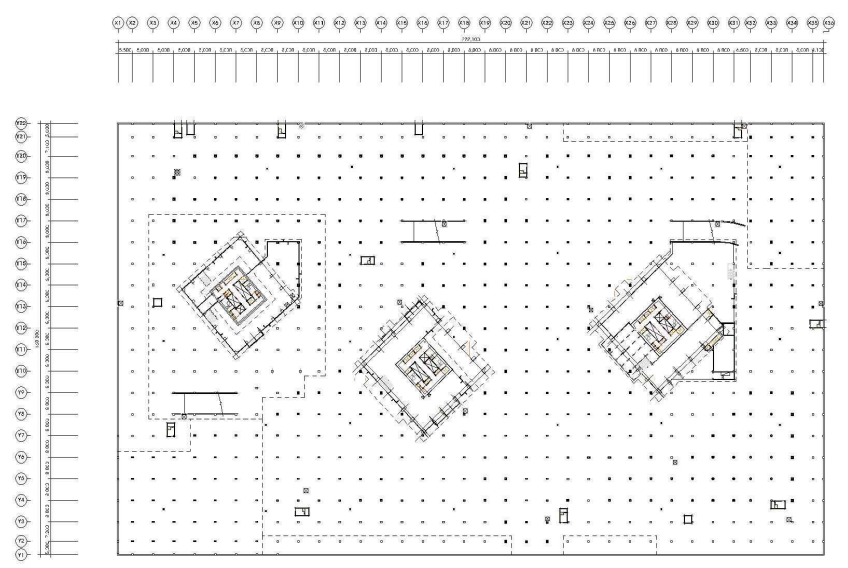

Figure 2. A case using long standard bar length in mat foundation 
Table 2. Reduction rate by standard bar length

\begin{tabular}{cccccc}
\hline $\begin{array}{c}\text { Applied } \\
\text { length(m) }\end{array}$ & 8 & 9 & 10 & 11 & 12 \\
\hline HD13 & 39.8 & 39.8 & 39.8 & 39.8 & 39.8 \\
HD19 & 771.87 & 762.65 & 756.84 & 749.03 & 753.26 \\
HD22 & 1355.56 & 1303.06 & 1295.64 & 1284.09 & 1274.68 \\
Total & 2147.22 & 2105.51 & 2092.28 & 2072.92 & 2067.74 \\
$\begin{array}{c}\text { Reduction } \\
\begin{array}{c}\text { Reduction rate } \\
(\%)\end{array}\end{array}$ & - & -41.71 & -54.94 & -74.31 & -79.49 \\
\hline
\end{tabular}

Therefore, if a rebar longer than $8 \mathrm{~m}$ is used, the number of splices can be reduced. Table 1 shows what happens to the rebar quantity needed for apartment complex A with mat foundation of $272.1 \mathrm{~m} \times 160.3 \mathrm{~m}$ when the rebar length is changed from $8 \mathrm{~m}$ to $12 \mathrm{~m}$. Compared with the $8 \mathrm{~m}$ rebar, considerable rebar quantity can be saved when a $9 \mathrm{~m}$ rebar is used. The loss can be reduced even further as the rebar gets longer. Consequently, if there is no problem with the onsite construction, we conclude that the greatest loss reduction will occur when the longest rebar length is used.

The loss reduction method by using longer rebars can also be identically applied to slabs which members are in a consistent direction like the mat foundation and also to beams that reinforce the main rebar in one continuous direction. However, since slab rebars have a small diameter but the beam main rebar has a thick diameter, actual constructability may show differently if the standard length becomes longer. If constructability decreases, then the construction period will lengthen and there might not be much cost reduction effect due to loss reduction. Therefore, we conclude that the constructability be fully taken into account for each member

\subsubsection{Reduction of splices at columns}

Generally columns are constructed at each floor and it is common that $\mathrm{B}$-class tension splice length is applied for the vertical bar. Usually a rebar with a wide diameter is used as the vertical bar of the column. Therefore, due to lap splices, the loss is considerable.

The next case study that we investigated was a mixed-use apartment building in which the internal columns were simultaneously arranged at two floors each. This arrangement was applied from the fourth floor to the 27th floor. The total loss that was reduced from the column vertical bar was 29.5 tons( 6.56 tons for D22, 11.18 tons for D25, 8.46 tons for D29, 3.29 tons for D32) for the whole of Building A. We analyzed this as a very significant loss reduction.

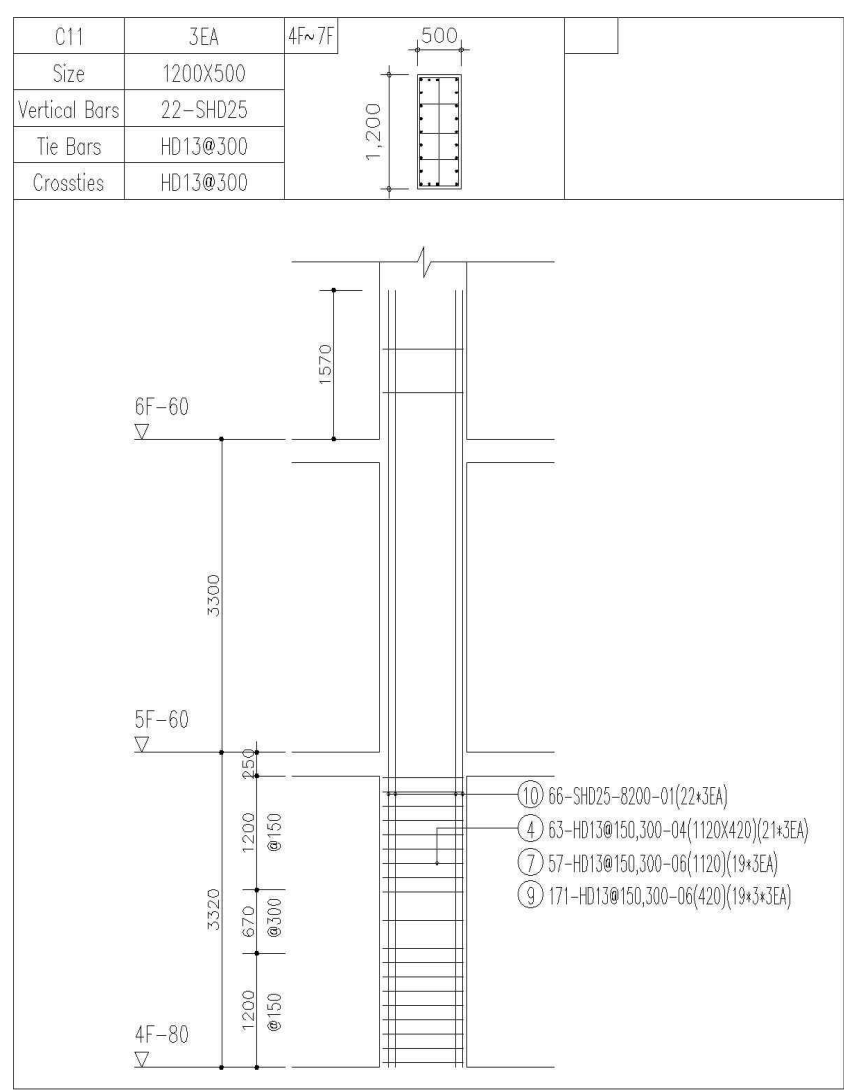

Figure 3. Placing drawing showing column vertical bars across two floors

\subsection{Reduction of Development Lengths}

\subsubsection{Loss reduction of column dowel bars}

The vertical column bars need to be anchored to the foundation. Therefore, the bars need to be embedded into the foundation as deep as the development length of the tension rebar. Recently, since mat foundations are being widely used and the height of the mat foundation is tall, the usual method used is to fix the vertical bar by installing a hook on the lower part of the mat foundation 


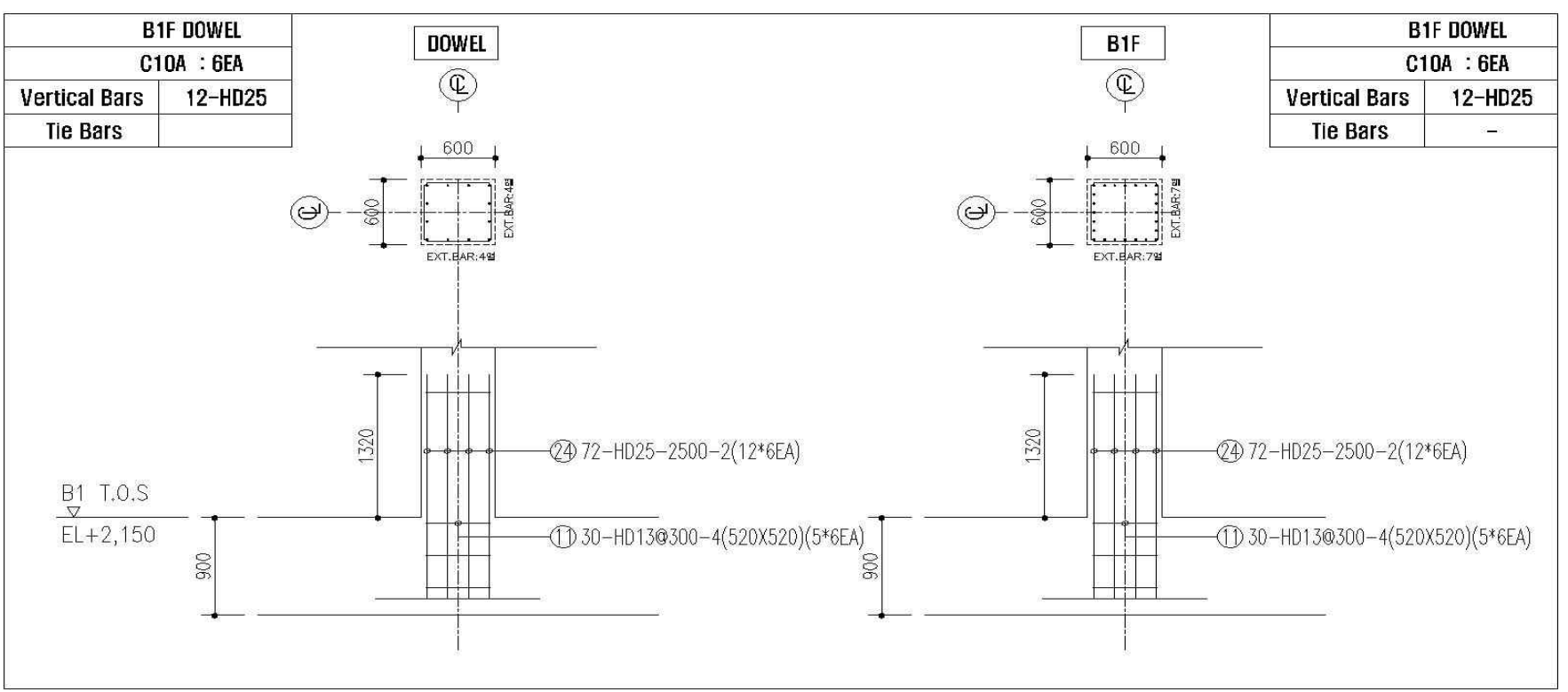

Figure 4. Placing drawing showing reduction of dowel bars

[6]. In this case, the higher the mat foundation the longer the development length and hence causes significant loss.

Next is the case study in which the number of the column dowel bars(SD400, D25) were reduced after a structural review. As can be seen in Figure 4, the number of main column bars in the first basement floor is 24. However, the number of dowel bars applied on the left is only 12 and the method to anchor only half the total number of bars was applied. By this method, a total of 10.51 tons was reduced. Much quantity was reduced because the diameter of the vertical bar was wide.

\subsection{Reduction of Lap Splice Length}

\subsubsection{Lap Splice length reduction for internal columns of underground apartment parking lots}

For the underground levels of a building, especially for a underground apartment parking lots, seismic design is not applied unlike floors above ground. In this case, vertical load from the upper levels greatly impacts the underground levels. Therefore, although tensile stress is dominant for the perimeter columns, compressive stress is dominant for the internal columns.

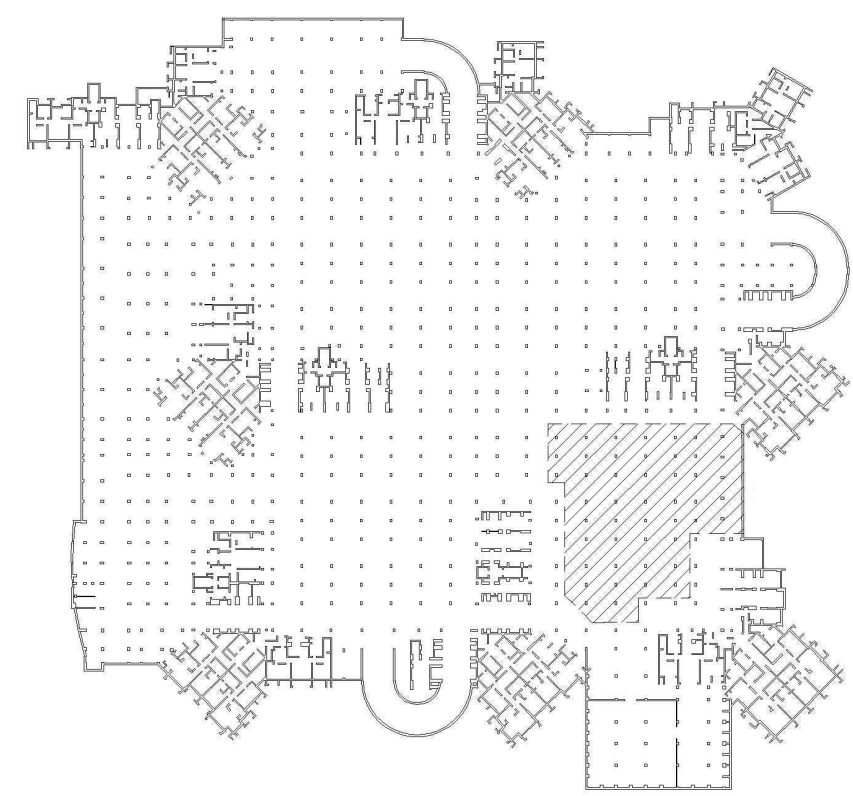

Figure 5. A case reducing lap splice length

In our next case study, after a structural examination, the splices of the internal columns of a underground apartment parking lot were installed as compression splices. The perimeter columns and block-type columns were excluded. In this case study, the compression splice lengths were applied to the slashed parts of the drawing. On the other parts, simultaneous bar arrangement was applied side by side. Therefore, loss reduction was only 


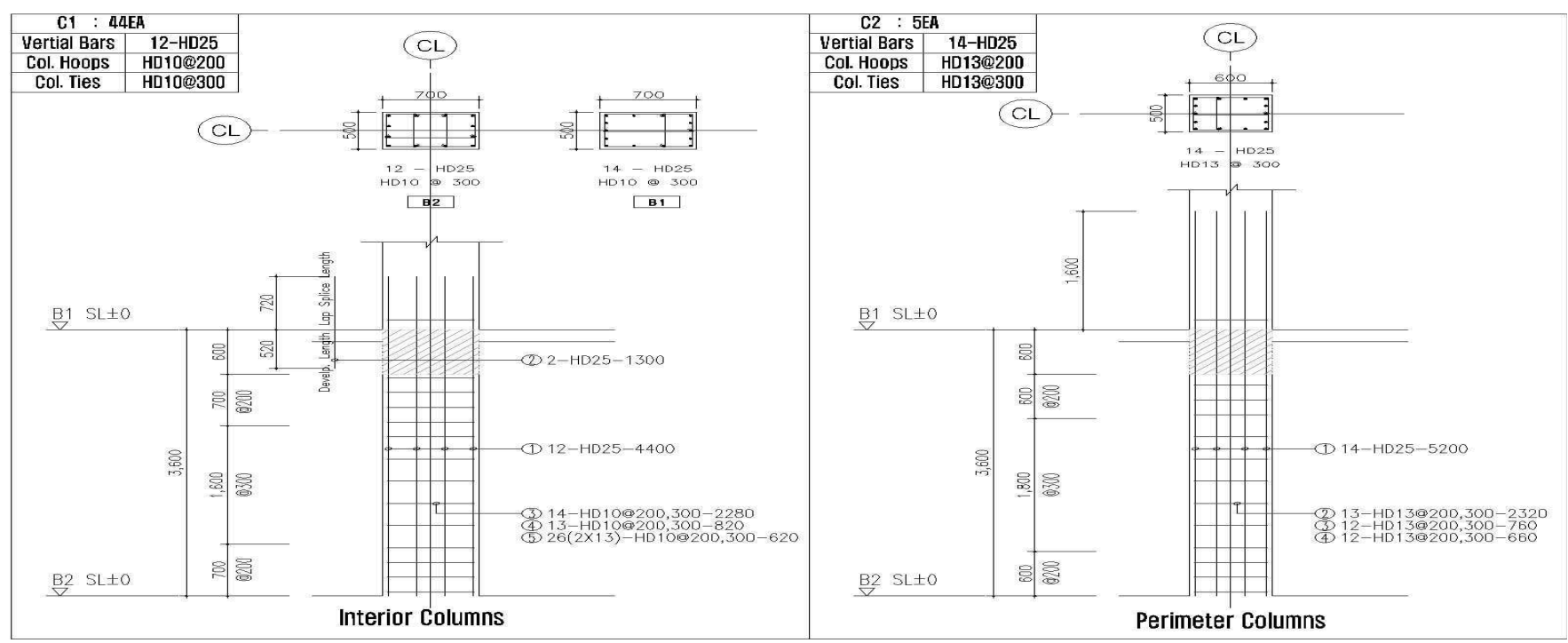

Figure 6. Placing drawing showing compression lap splice length

analyzed for the slashed parts.

In the slashed area, the number of columns that were placed as compression splices after a structural review was 44. In each column, 12 D25 rebars were placed as vertical bars. As can be seen on Figure 5, tensile lap splice lengths were applied to the perimeter columns on the right. However, even though compression splice lengths were applied only to parts of the internal columns on the left side, we analyzed the total loss reduction to be 1.85 tons. Generally, the rebars are thick for the column vertical bars and therefore we conclude that if our method is to be applied to the total area, a very significant loss can be reduced.

\subsection{Other}

\subsubsection{Reduction of stirrup for internal beams of underground apartment parking lot}

When shearing and torsion occurs at the same time or if seismic design is applied, beam stirrups have to be placed as a closed-type stirrup. However, since seismic designs are not necessary for underground parking lots, the internal beams can be placed as U-shaped stirrups for which no upper piece of the capped stirrup-tie are needed. This placing can be seen on Figure 7. The spandrel beams have been excluded. cap-ties also are responsible for holding the position of the beam longitudinal bar. Therefore, we can reduce rebar loss if we can install one cap-tie for every three beams.

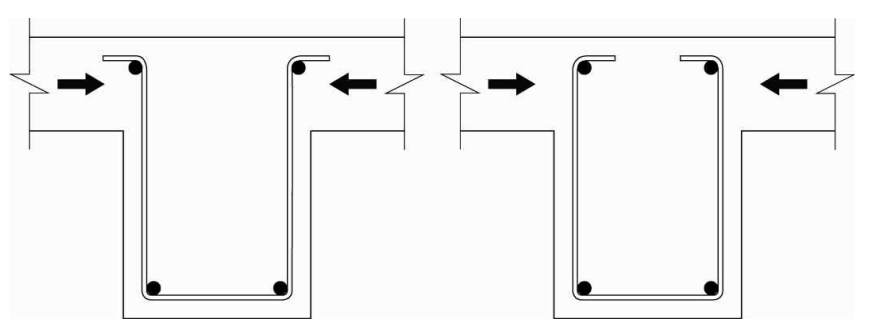

Figure 7. Open stirrups

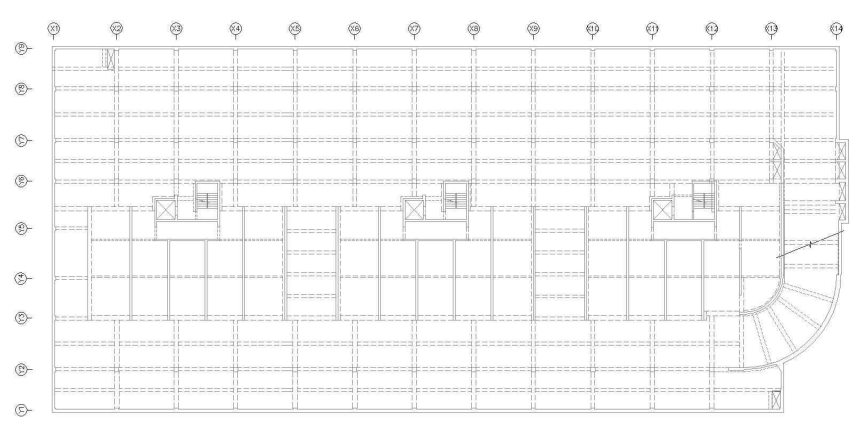

Figure 8. A case reducing upper piece of the capped stirrup-tie

In this case(figure 8), one of upper piece of the capped stirrup-tie was installed for every three internal beams of the first basement apartment parking lot. The rebar sizes used for the stirrups are D10, D13 and D16. We found 
Table 3. Loss deduction method

\begin{tabular}{|c|c|c|c|}
\hline Element & Loss Reduction Method & $\begin{array}{l}\text { Structure } \\
\text { Review }\end{array}$ & $\begin{array}{l}\text { Constructability } \\
\text { Review }\end{array}$ \\
\hline Foundation & (1) Reduce number of splices by using rebars with long standard lengths & & Needed \\
\hline \multirow{4}{*}{ Column } & (1) Reduce number of dowel bars to be embedded into foundation & Needed & \\
\hline & (2) Reduce development length of dowel bars to be embedded into foundation & & Needed \\
\hline & (3) Reduce number of splices using long vertical bars across two floors & & Needed \\
\hline & $\begin{array}{l}\text { (4) Reduce lap splice length by applying compression splice to intemal columns of underground apartment } \\
\text { parking lots }\end{array}$ & Needed & \\
\hline \multirow[b]{2}{*}{ Wall } & (1) Reduce development length of dowel bars to be embedded into foundation & & Needed \\
\hline & $\begin{array}{l}\text { (2) For perimeter walls of underground floors, reduce splice length by applying compression lap splice } \\
\text { lengths to the internal vertical rebars. }\end{array}$ & Needed & \\
\hline \multirow{3}{*}{ Beam } & (1) Reduce number of lap splices by using rebars with long standard lengths & & Needed \\
\hline & (2) Reduce upper Cap-ties by placing stirrups of underground internal beams as open-types & Needed & \\
\hline & (3) Reduce lap splice length by placing bars to become splices in the compression splice sections & & Needed \\
\hline Slab & (1) Reduce number of splices by using rebars with long standard lengths & & Needed \\
\hline
\end{tabular}

that a total of 3.73 tons $(1,56$ tons for D10, 1.73 tons for D13, 0.44 tons for D16) in 1st basement of underground parking lot was reduced for the entire 1st basement floor. Considering that relatively thin rebar sizes for stirrups are used, we conclude that a significant loss can be reduced if the basement area is larger and the number of girder and beam is larger.

\section{Loss Reduction Method of Rebar}

\subsection{Loss reduction method of rebar}

The following is a summary of the loss reduction methods for each element. The methods are based on the actual case studies that have been presented up till now and interviews with field experts.

For members that are widely spread out in the horizontal direction such as foundations, beams, and slabs, rebars of a fixed standard length should be placed using lap splices. In this case, we conclude that loss reduction of rebars can be brought about if rebars longer than the previous $8 \mathrm{~m}$ are used. However, the longer the standard length, the higher the possibility will rise that constructability will decrease. Therefore, we conclude that constructability be fully taken into account before setting on an appropriate standard length.
Dowel bars are placed to anchor columns and walls to the foundation. The higher the foundation, the more quantity of rebars is used. In accordance with domain code, the rebars only need to be embedded as deep as the development length. In actuality, however, the rebars are fixed onto the lower part of the mat foundation even if concrete pouring is necessary so they do not move. Therefore, the height of the foundation impacts the rebar quantity. Consequently, wall dowel bars should be fixed to the lower vertical bars of the foundation at $1.6 \mathrm{~m}$ $2.0 \mathrm{~m}$ intervals. The rest should be embedded as deep as the development length. In the case of columns, only the four vertical bars positioned at the column corners should be fixed above the lower main bar of the foundation. The rest of the rebars should be embedded into the foundation as deep as the development length. We conclude that such construction will reduce rebar loss.

For the other columns, if long vertical bars across two floors are used, then the rebar loss can be reduced as much as the column lap splice length. In addition, we also conclude that the lap splice length can be reduced if after a structural review, the underground internal columns for which compression splices can be applied are determined.

For the wall that resists earth pressure, while placing the bars, the vertical rebars that are placed on the outside resist the tension and the vertical rebars placed 
on the inside resist the compression. Therefore, if compression lap splices are applied to the inside vertical rebars, we conclude that the lap splice length can be reduced.

For the beam, if after a structural review, the underground internal beams are placed as open stirrups, we conclude that rebar loss for upper cap-ties can be reduced. In addition, specifications require that splicing occurs at the compression sections when splicing the beam longitudinal bars. However, in most cases, this requirement is ignored on grounds of constructability. The compression sections are not considered and tensile splices are placed. In cases beams with consistent spans are set in a continuous manner, however, splices can occur at compression sections if standard lengths of appropriate lengths are used. We conclude such splicing can reduce that much lap splice length.

The loss reduction methods presented in this study did not take constructability into consideration. Therefore, in cases where a constructability review is necessary, we recommend that the review be taken. A simple loss reduction method may worsen constructability and lead to construction delay or lowering of quality. This will result ultimately in the increase of construction costs. Therefore, we recommend that constructability be fully taken into account.

\subsection{Application to Cases}

In this section, we analyzed how much loss reduction will occur if we applied the reduction methods that we presented to actual cases. Of the reduction methods, we excluded those that needed constructability reviews. The method which uses a standard length longer than $8 \mathrm{~m}$ for the foundation, beam, and slab needs a constructability review. However, we concluded that there is not problem with the constructability and applied the longest length of $12 \mathrm{~m}$.

Figure 9 shows 1st basement of the applied case for culture and meeting facility(basement area $5,422.0 \mathrm{~m}^{2}$ ). As we have previously presented in Table 2, some loss

Table 3. The results of applying loss reduction method

\begin{tabular}{|c|c|c|c|c|c|c|c|c|c|}
\hline \multicolumn{2}{|c|}{ Part } & HD10 & HD13 & HD16 & HD19 & HD22 & SHD25 & Total & Note \\
\hline \multirow{3}{*}{$\begin{array}{c}\text { Founda- } \\
\text { tion }\end{array}$} & Before & - & 5.97 & 14.68 & 282.72 & 1.89 & 9.02 & 314.28 & $8 \mathrm{~m}$ standard length \\
\hline & After & - & 5.97 & 14.60 & 276.78 & 1.89 & 9.02 & 308.26 & $12 \mathrm{~m}$ standard length \\
\hline & Difference & - & - & 0.8 & 5.94 & - & - & 6.02 & \\
\hline \multirow{3}{*}{$\begin{array}{l}\text { Column } \\
\text { dowels }\end{array}$} & Before & 0.95 & 1.34 & - & - & 18.05 & 1.67 & 22.01 & Total tensile anchorage \\
\hline & After & 0.95 & 1.34 & - & - & 6.48 & 1.18 & 9.96 & Applied $50 \%$ dowel rebar \\
\hline & Difference & - & - & - & - & 11.57 & 0.49 & 12.05 & \\
\hline \multirow{3}{*}{ Columns } & Before & 6.91 & 2.99 & - & - & 40.08 & 2.83 & 52.80 & Total tensile lap splice \\
\hline & After & 6.91 & 2.99 & - & - & 37.15 & 2.83 & 49.87 & Compression lap splice for internal columns \\
\hline & Difference & - & - & - & - & 2.93 & - & 2.93 & \\
\hline \multirow{2}{*}{$\begin{array}{c}\text { Wall } \\
\text { dowels }\end{array}$} & Before & 0.32 & 6.77 & 4.47 & 3.66 & 2.15 & - & 17.36 & Total tensile anchorage \\
\hline & After & 0.32 & 5.16 & 2.95 & 0.96 & 0.59 & - & 9.98 & Reduce development length, intemal compression splice \\
\hline \multirow{3}{*}{ Beams } & Before & 12.66 & 19.66 & 0.12 & - & - & 115.93 & 148.37 & $8 \mathrm{~m}$ standard length, closed-type stirrup \\
\hline & After & 10.98 & 17.46 & 0.12 & - & - & 113.54 & 142.12 & 12 m standard length, open-type stirrup \\
\hline & Difference & 1.67 & 2.20 & - & - & - & 2.39 & 6.25 & \\
\hline \multirow{3}{*}{ Slabs } & Before & 15.47 & 14.28 & 1.89 & - & - & - & 31.64 & $8 \mathrm{~m}$ standard length \\
\hline & After & 15.14 & 14.28 & 1.89 & - & - & - & 31.31 & 12 m standard length \\
\hline & Difference & 0.33 & - & - & - & - & - & 0.33 & \\
\hline \multirow{3}{*}{ Total } & Before & 36.30 & 51.00 & 21.16 & 286.38 & 62.16 & 129.45 & 586.46 & \\
\hline & After & 34.31 & 47.20 & 19.56 & 277.74 & 46.11 & 126.58 & 551.50 & \\
\hline & Difference & 1.99 & 3.81 & 1.60 & 8.64 & 16.04 & 2.87 & 34.95 & \\
\hline
\end{tabular}


reduction methods need structure reviews. However, in these cases, we assumed that the reviews had taken place and applied our methods.

For the foundation, the reduction is the difference in quantity from the previous $8 \mathrm{~m}$ rebar with the $12 \mathrm{~m}$ rebar. In the case of columns, we analyzed the method in which column dowel bars were reduced by $50 \%$ and the method in which the internal columns were spliced with compression splices. For the walls, we also applied two methods. One method was to reduce the number of the dowel bars to be embedded into the foundation. The other method was to reduce the lap splice length by applying tensile lap splice length to the perimeter vertical rebars and applying compression splice lengths to th einternal vertical rebars. For the beams, we analyzed the method of using a $10 \mathrm{~m}$ rebar in place of the previous 8 $\mathrm{m}$ rebar. We also analyzed the method of installing one cap-tie rebar to every three internal beams.

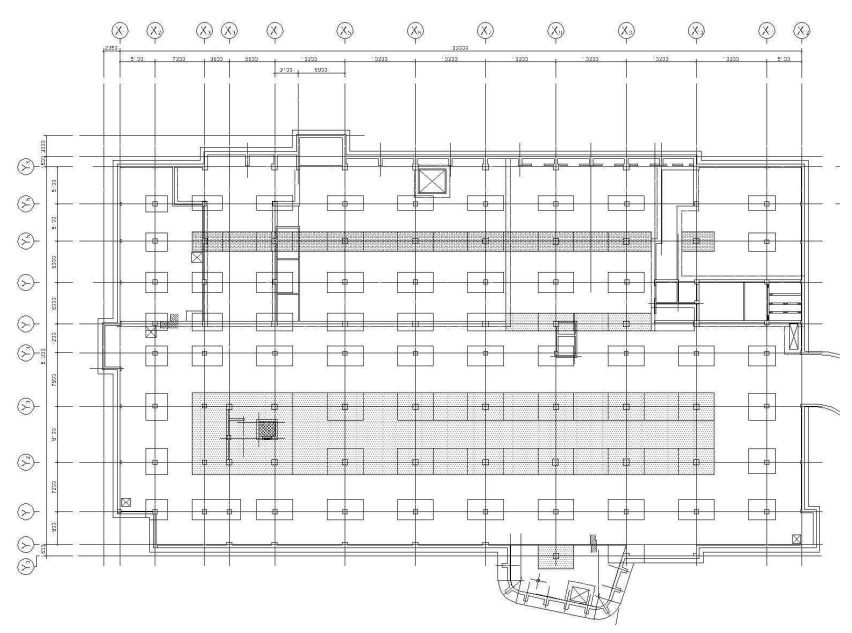

Figure 9. A case for applying loss reduction method

The application and reduction results are as follows: 6.02 tons at the foundation, 12.05 tons at the column dowels, 2.93 tons at the columns, 7.38 tons at the wall dowels, 6.26 tons at the beams, and 0.33 tons at the slabs. We found that there was much loss reduction for the foundation dowels which use relatively wide diameter bars. Although the rebar diameter used for the wall dowels is narrow and the method was only applied to the perimeter walls, there nevertheless was a loss reduction. However, for the application to one-floor slabs, there was not much loss reduction.
Looking at overall results, the biggest loss reduction occurred for those rebars with a wide diameter. For the cases where our methods were applied, the total loss reduction was 34.95 tons. We therefore expect that a considerable loss reduction will occur if our methods are applied.

\section{Conclusion}

In this study, we presented loss reduction methods for rebars through structure reviews and before the preparation of the placing drawings.

To come up with our methods, we analyzed actual case studies based on placing drawings and then analyzed the loss reduction for each case. Looking over previous cases, we found that various reduction methods were being applied mainly to rebars with wide diameters. Specifically the following were the methods used: method to reduce the number of splices by using lengths longer than standard lengths at the foundation, method to reduce number of splices by using long column vertical bars across two continuous floors, method of reducing number of column dowel bars that are to be anchored to the foundation, method of reducing splice length by applying compression splice to the splices of the internal columns of a underground apartment parking lot, and a method to reduce rebar loss for cap-ties by applying the internal beam stirrups of an underground parking lot as open-type stirrups.

In addition, we presented loss reduction methods of rebars based on our analyzed results and interviews with detailers. We also analyzed the loss reduction by applying our methods to actual construction cases. As our analysis result shows, considerable loss reduction can take place if our methods are applied.

This study presented loss reduction methods of rebars by improving rebar arrangement. However, we did not consider constructability in our study. If a rebar with a long standard length is used, workers will have difficulty moving and handling the rebars. Additionally, if two-floor columns are placed at one time, such a placing may negatively impact concrete pouring and following 
construction work. Therefore, we recommend that the constructability be fully taken into account when deciding on rebar placing method.

\section{Acknowledgement}

This research was supported by a grant(05CIT-D05-01) from Construction Technology Innovation Program funded by Ministry of Land, Transport \& Maritime Affairs of Korean government.

\section{References}

1. Jo HH, Kang GI. Survey on Actual Condition of Rebar Manufacturing Works in Domestic. Journal of the Fall Conference of Architectural Institute of Korea 1996;16(2):771-774.

2. Korea Concrete Institute. Design Code and Commentary for Concrete Structures. Kimoondang 2008.

3. Park UY, Kim BJ, Jung HO, Yun SH, Cho HH, Kang KI. A Study on the Improvement of Reinforcing Bar Detailing. Journal of the Korea Institute of Building Construction 2008;8(1):83-90.

4. Kim SG, Kim MH. A Study on the Development of the Optimization Algorithm to Minimize the Loss of Reinforcement Bars. Journal of the Architectural Institute of Korea 1991;7(3):385-391.

5. Kim YI, Lee JY, Kim JS, Jeon YI. A System Development for Steelbar Quantity Surveying and Optimization of the Loss. Journal of the Architectural Institute of Korea 1996;12(9):173-179.

6. Jeong HO, Cho HH, Park UY. A Study on the Improvement of Erection Bar Detailing in Domestic Building Construction. Journal of the Korea Institute of Building Construction 2009;9(2):39-46.

7. Kim JY, Kim GH. A Study on Economic Evaluation Method of Coupler Splice for High Strength(SD500) Reinforcement. Journal of the Korea Institute of Construction Engineering and Management 2007;8(2): 136-145.

8. Kim JY, Kim DW. A Study on the Economic Evaluation Model of Splice of Reinforcement Bar(SD500). Journal of the Korea Institute of Building Construction 2008;8(1):71-76.

9. Park WY, Joe SY, Kang KI. A Study on Rebar Detailing Optimization Using Genetic Algorithm. Journal of the Architectural Institute of Korea
2003;19(10):125-132.

10. Jo HH, Park UY, Kang TK, Park HY, Yun SH, Hur YK. Analysis of Re-bar Manufacturing System in Plant and its Facilitate Method. Journal of the Korea Institute of Construction Engineering and Management 2007;8(1):57-65. 